\title{
KARTUN CERIA (CERITA REMAJA INDONESIA) TENTANG PENDIDIKAN SEKS SEBAGAI PENUNJANG MATERI AJAR SISTEM REPRODUKSI DI SMP
}

\author{
Hafizah Saleh $^{1)}$, Binari Manurung ${ }^{2)}$, Ely Djulia ${ }^{3)}$ \\ E-mail: djulia247@gmail.com \\ ${ }^{12233)}$ Program Studi Pendidikan Biologi Pascasarjana, Universitas Negeri Medan, Sumatera Utara, Indonesia
}

\begin{abstract}
This development research aims to determine: (1) Content Feasibility; (2) Feasibility of Presentation, (3) Feasibility of Language (Readability), and (4) Feasibility of Design of Ceria Cartoon Calendar (Indonesian Youth Story) for Junior High School students. The research procedure uses the Thiagarajan development model which consists of four stages (four-D models), namely: define stage, design stage, develop stage and disseminate. The feasibility analysis was carried out using a questionnaire instrument which was assessed by three parties consisting of Expert Validators, Biology Teacher Reviewers, and a Student Perception Questionnaire of the Cheerful Cartoon Calendar (Indonesian Youth Story) Biology Class IX SMP PGRI 24 Medan. Analysis. The results of this study showed that: (1) The Feasibility of the Contents of the Ceria Cartoon Calendar (Indonesian Youth Story) obtained good criteria, (2) the Feasibility of the Presentation of the Cheerful Cartoon Calendar (Indonesian Youth Story) obtained very good criteria, (3) the Feasibility of Language (Readability) Calendar Ceria Cartoon (Indonesian Youth Story) obtained good criteria, and (4) the Feasibility of the Ceria Cartoon Calendar (Indonesian Youth Story) Design Feasibility criteria obtained very good eligibility criteria. The results of this study imply that the Ceria Cartoon Calendar (Indonesian Youth Story) Biology has good criteria to be used for adolescent students, especially in class IX SMP in conveying information about knowledge about sex education in supporting reproductive system materials in the classroom.
\end{abstract}

Keywords: Cheerful Cartoons (Indonesian Youth Stories) Biology, Sex Education, and the Reproductive System

\section{PENDAHULUAN}

Seks merupakan topik yang sangat menarik, terutama bagi kaum pra-remaja, remaja dan dewasa. Bukan hanya remaja dan orang dewasa yang perlu diberi pengetahuan mengenai pendidikan seks, pendidikan seks perlu diberikan sedini mungkin bahkan sejak usia anak-anak. Terkait maraknya kasus-kasus pelecehan seksual pada anak dibawah umur maupun dewasa, dunia prostitusi seks bebas di kalangan remaja maupun dewasa bahkan di kalangan anak-anak dibawah umur yang kerap terjadi baru-baru ini. Oleh karena itu, pendidikan seks sangat dibutuhkan untuk menyelamatkan generasi muda kita supaya tetap waspada dan berada di jalan yang benar, bertindak sesuai nilai moral, agama dan budaya yang berlaku.

Permasalahan utama yang muncul pada anak pra-remaja yang sedang memasuki masa pubertas adalah masa awal kematangan seksual, yakni suatu periode di mana seorang anak mengalami perubahan fisik, hormonal, dan seksual serta mampu melakukan proses reproduksi (Hurlock, 1978). Pada perkembangan intelegensia anak mampu berpikir abstrak, senang memberi kritik, ingin mengetahui hal-hal baru, sehingga memiliki rasa penasaran yang tinggi dan muncul perilaku ingin mencobakan berbagai hal (Depkes RI, 2001). Pada masa transisi inilah, anak semakin kritis terhadap masalah seksual dan semakin penting peran orangtua dan pendidik untuk membimbing 
anak pendidikan yang memadai tentang pubertas dengan bijak. Menurut Vera Itabiliana Hadiwidjojo, psikolog dari Lembaga Psikologi Terapan UI, "Edukasi seks itu adalah diskusi yang harus terus-menerus dilakukan orangtua dan pendidik bersama anaknya."

Seringkali orangtua dan pendidik merasa kesulitan dalam memberikan bimbingan dan arahan baik berupa diskusi maupun membicarakan edukasi seks bersama anak. Kurangnya pengetahuan mengenai masa pubertas dan edukasi seks pada anak dapat memicu munculnya penyimpangan penyimpangan dan kenakalan-kenakalan remaja seperti narkoba, penyakit menular seksual, dan kehamilan di luar nikah. Ada baiknya orangtua dan pendidik menggunakan buku pedoman yang membahas mengenai seks usia remaja kepada anak-anaknya. Namun, buku pedoman yang kurang interaktif tidak akan efektif dalam memberikan bimbingan. Banyak dijumpai buku-buku ilmiah yang isinya hanya hal-hal yang bersifat edukatif dan berisi informasi-informasi yang masih sangat dasar dan bahasa yang kaku. Padahal, anak, pendidik dan orangtua memerlukan suasana santai dan tidak tegang serta diiringi dengan humor-humor ringan tetapi tetap dengan pandangan dewasa, serta buku perlu penyesuaian bahasa dengan usia anak. Pengembangan diri dalam diri seorang anak dapat diartikan sebagai individu yang sedang mengembangkan pengetahuan, keterampilan dan kemampuan lain melalui minat dan usaha.

Dalam pendidikan formal di sekolah, pendidikan seks diantaranya disampaikan dalam pembelajaran IPA Biologi pada materi Sistem Reproduksi Manusia, namun sejauh ini umumnya pembelajaran materi tersebut lebih mengedepankan struktur dan fungsi, belum banyak mengaitkan dengan sikap siswa terhadap perkembangannya saat mengalami pubertas.

Upaya meningkatkan kualitas pembelajaran tentang Sistem Reproduksi telah dilakukan melalui penelitian quasy experiment dengan menerapkan model kooperatif think pare share menggunakan video (Sagala \& Djulia, 2016), serta hubungan antara metakognisi kesehatan reproduksi dengan persepsi perilaku seksual siswa (Sapitri, Sipahutar, Djulia, 2014). Namun masih minim penelitian yang membangun sikap dan respons positif siswa terhadap perkembangan pubertas.

Sebagaimana mestinya, anak memerlukan buku sebagai sarana penunjang pengembangan diri mereka karena melalui buku terdapat pendekatan berupa unsur interaktif (aksi-reaksi) yang membuat anak cepat menangkap topik bahasan. Buku interaktif mempunyai trik-trik khusus untuk dapat menarik minat baca anak, salah satunya adalah memberikan sebuah permainan kecil diselasela membaca sehingga anak tidak cepat jenuh. Buku yang memiliki tampilan yang menarik dengan memiliki ilustrasi pendukung berupa gambar merupakan salah satu cara untuk memudahkan masuknya informasi ke otak anak-anak. Dengan tampilan layout yang menarik, serta minimnya tulisan yang sifatnya ilmiah yang cenderung lebih mudah untuk dimengerti. Rasa ingin tahu yang tinggi membuat anak aktif dan kritis dalam bertanya kepada orangtua dan pendidik, buku interaktif akan menjadi pedoman yang baik dan merangsang minat baca anak serta mengupayakan anak mendapat jawaban atas setiap pertanyaan.

Untuk itu diperlukan media cetak berupa kartun interaktif berupa modifikasi yang lebih menarik dari buku biasanya. Kartun interaktif ini mudah disimpan dalam jangka waktu yang panjang serta mudah dibaca di mana saja tanpa perlu membuat mata lelah. Lain halnya ketika membaca melalui e-book maupun browsing di internet, pendampingan serta bimbingan langsung dalam hal penggunaan gadget menjadi kunci belajar anak, sayangnya perbedaan generasi membuat orangtua terlihat gagap teknologi dan tidak semua orangtua paham mengenai kecanggihan teknologi. Selain kecanggihan teknologi masa kini, tidak semua orang memiliki status ekonomi yang sama, edukasi melalui gadget hanya dapat dilakukan di kalangan menengah ke atas. Penting bagi para orangtua dan pendidik untuk membentuk pemahaman anak, bahwa gadget bukanlah alat utama belajar, tetapi hanya instrumen paling efisien. Dan buku adalah cara bagi mereka untuk lebih mengerti proses belajar hingga menghasilkan suatu produk modifikasi dari buku adalah kartun interaktif. Perancangan kartun interaktif ini diberi nama CERIA (Cerita Remaja Indonesia) yang 
diambil dari sebuah situs BKKBN yang berisi tentang curhatan para remaja seputar seks. Situs CERIA yang diberikan oleh BKKBN belum menjadi solusi bagi remaja untuk menanggulangi minimnya pengetahuan remaja. Oleh sebab itu, kajian pembelajaran biologi di SMP, pada bahasan Sistem Reproduksi Manusia memerlukan inovasi produk media pembelajaran berupa kartun interaktif sebagai penunjang materi Sistem Reproduksi Pra - Remaja. Produk penelitian ini bertujuan untuk memberikan pemahaman yang benar tentang materi pendidikan seks meliputi struktur dan fungsi sistem organ reproduksi, identifikasi dewasa, kesehatan seksual, penyimpangan seks, kehamilan dan perkawinan dini dalam meminimalisir masalah seks bebas melalui kartun interaktif bergambar CERIA (Cerita Remaja Indonesia) dibawah bimbingan orangtua dan pendidik. Manfaat penelitian ini ialah menghasilkan kartun interaktif CERIA yang dapat dijadikan acuan serta penunjang materi ajar dalam sosialisasi pendidikan seks baik di lingkungan sekolah maupun di masyarakat.

\section{METODE PENELITIAN}

Penelitian pengembangan produk Kartun Ceria (Cerita Remaja Indonesia) dilaksanakan bulan November 2017 pada siswa kelas IX SMP PGRI 24 Medan Jalan Kasuari II Medan Denai. Penelitian ini termasuk penelitian pengembangan yang dikemukakan oleh Thiagarajan, dkk (1974) dengan menggunakan Model pengembangan Four (4)D, yaitu: tahap define (pendefinisian), tahap design (perancangan), tahap develop (pengembangan) dan disseminate (penyebaran) melalui media Kalender Kartun Ceria (Cerita Remaja Indonesia) dengan materi sistem reproduksi manusia. Data dikumpulkan menggunakan instrument angket. Instrumen yang dipakai untuk menilai produk yang telah dikembangkan yaitu berupa: (a) Angket materi/isi; (b) Angket desain; (c) Angket Guru berupa kritik ataupun saran pada kalender kartun ceria (Cerita Remaja Indonesia); dan (d) Angket Siswa untuk melihat respon siswa terhadap produk yang dikembangkan.

Data yang diperoleh dari setiap kriteria angket diolah dengan rumus:

$$
\mathrm{P}=\frac{n}{N} \mathrm{X} 100 \%
$$

(Sudijono, 2005)

\section{Keterangan:}

$\mathrm{P} \quad=$ Persentase kategori

$\mathrm{n} \quad=$ Jumlah skor jawaban kategori yang dipilih

$\mathrm{N} \quad=$ Total skor ideal

Kemudian dilakukan analisis secara deskriptif dengan menghitung persentase skor untuk setiap kriteria pada buku ajar yang dikembangkan, sehingga diperoleh persentase kelayakan dari aspek yang dinilai dengan rumus:

Persentase angket $=$

$$
\frac{\text { Jumlah skor yang diperoleh }}{\text { Jumlah total skor ideal }} \text { 100\% }
$$

Dari hasil perhitungan menggunakan rumus di atas menghasilkan angka dalam bentuk persen. Perolehan skor tersebut selanjutnya dimaknai dengan kalimat bersifat kualitatif. 
Jurnal Biogenesis Vol. 17 (2): 69-80, 2021

(c) Program Studi Pendidikan Biologi FKIP Universitas Riau

e-ISSN : 2776-1924

\section{HASIL DAN PEMBAHASAN}

\section{Tahap Define (Pendefinisian)}

Tahap define (pendefinisian) dalam penelitian ini yaitu menganalisis kebutuhan siswa mengenai cara penyampaian materi sistem reproduksi agar siswa dengan lebih mudah dapat memahami materi pembelajaran sistem reproduksi dan menjawab tugas-tugas mengenai sistem reproduksi dari guru biologi IPA sehingga tujuan pembelajaran dapat tercapai dengan baik. Analisis kebutuhan siswa ini dilakukan dengan mengumpulkan informasi melalui guru-guru di SMP PGRI 24 Medan dengan mengidentifikasi faktor-faktor pendukung dan penghambat proses pembelajaran IPA pada siswa kelas IX SMP PGRI 24 Medan. Analisis kebutuhan dilakukan bertujuan untuk mengetahui masalah pada peserta didik dalam mencapai tujuan pengembangan pembelajaran yang mengarah pada peningkatan mutu pendidikan, yakni dengan mengetahui topik-topik materi pelajaran IPA biologi yang benar-benar dibutuhkan peserta didik, format materi sajian yang dibutuhkan, model sajian materi pelajaran yang efektif, dan topik materi pelajaran yang tepat untuk disajikan.

Pada hasil tahap define (pendefinisian) dalam penelitian ini dalam menganalisis kebutuhan siswa di SMP PGRI 24 Medan diperoleh bahwa: sarana dan prasarana di sekolah tersebut masih belum mencukupi kebutuhan belajar siswa, dimana siswa belajar apa adanya dengan menggunakan buku ajar berbagi bersama ketika proses pembelajaran berlangsung, sehingga ditemukan tidak adanya buku penunjang dalam kegiatan belajar mengajar. Dengan demikian hasil tahap define (pendefinisian) dalam penelitian ini diperoleh simpulan bahwa pentingnya sumber belajar maupun media belajar dalam menunjang proses pembelajaran di dalam kelas yakni dengan memilih media pembelajaran berbentuk Kalender Kartun Ceria (Cerita Remaja Indonesia) yang memuat materi pendidikan seks sebagai penunjang materi sistem reproduksi.

\section{Tahap Design (Perancangan)}

Tahap design (perancangan) dalam penelitian ini yaitu merancang media Kalender Kartun Ceria (Cerita Remaja Indonesia) yang berisikan tentang pendidikan seks sebagai penunjang materi sistem reproduksi. Perancangan Kalender Kartun Ceria (Cerita Remaja Indonesia) membahas mengenai karakter tokoh kartun Ceria (Cerita Remaja Indonesia), kelayakan isi mengenai pokok bahasan berupa pendidikan seks untuk mendukung materi sistem reproduksi kelas IX SMP, kelayakan penyajian berupa bentuk tampilan desain gambar pada kalender kartun Ceria (Cerita Remaja Indonesia), dan kelayakan bahasa yang disajikan pada kalender kartun Ceria (Cerita Remaja Indonesia) yang disesuaikan dengan Ejaan Yang Disempurnakan yang benar dalam bahasa Indonesia serta menggunakan peristilahan mengenai pendidikan seks sebagai penunjang materi sistem reproduksi sesuai dengan karakter siswa remaja sehingga siswa tersebut dapat dengan mudah memahami materi sistem reproduksi yang tersaji di dalam kalender kartun Ceria (Cerita Remaja Indonesia) ini. Design (perancangan) Kalender Kartun Ceria (Cerita Remaja Indonesia) dilakukan dengan menggambar sketsa gambar kartun Ceria (Cerita Remaja Indonesia). Contoh Design (Perancangan) Kalender Kartun Ceria (Cerita Remaja Indonesia) disajikan pada Gambar 1. 
Gambar 1. Contoh Design (Perancangan) Tampilan Cover Kalender Kartun Ceria (Cerita Remaja Indonesia)

Kemudian pada langkah berikutnya melakukan scan gambar tersebut kedalam alat paint tablet dengan pulpen digital untuk dilukis kembali dalam penegasan garis struktur gambar menjadi lebih jelas. Alat Paint Tablet dengan Pulpen Digital digunakan untuk Melukis Kembali Gambar sehingga menjadi Lebih Jelas disajikan pada Gambar 2.

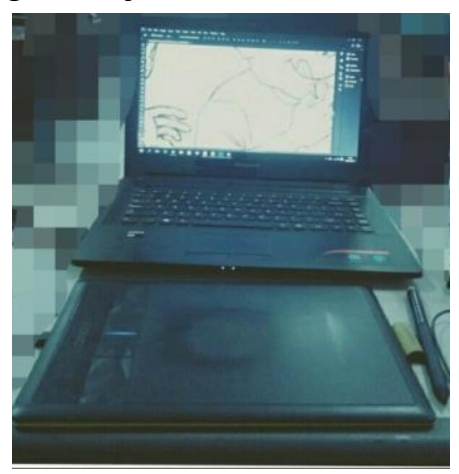

Gambar 2. Alat Paint Tablet

Kemudian setelah mempertegas scan, maka dilakukan pewarnaan, sehingga hasil yang diperoleh dapat dilihat. Tampilan Cover Kalender Kartun Ceria (Cerita Remaja Indonesia) disajikan pada Gambar 3.

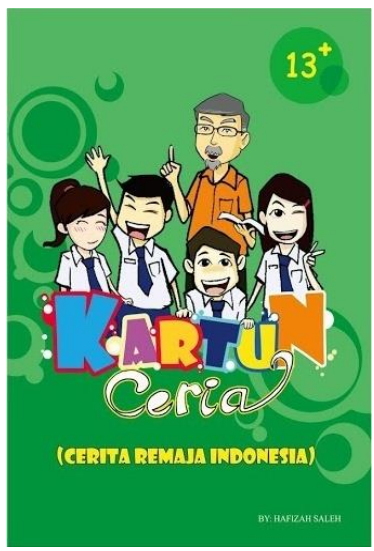

Gambar 3. Tampilan Cover Kalender Kartun Ceria (Cerita Remaja Indonesia) 


\section{Tahap Develop (Pengembangan)}

Tahap develop (pengembangan) dalam penelitian ini yaitu melakukan diskusi mengenai aspek-aspek penilaian Kalender Kartun Ceria (Cerita Remaja Indonesia) ini yang meliputi kelayakan isi, penyajian, bahasa, dan kegrafikan/desain kepada validator ahli materi, dan desain penyajian dari Kalender Kartun Ceria (Cerita Remaja Indonesia) ini sebelum dilakukan pengujian kepada siswa kelas IX SMP PGRI 24 Medan.

Pada kelayakan isi, Kalender Kartun Ceria (Cerita Remaja Indonesia) ini memuat materi Pendidikan seks dengan memberikan pengetahuan tentang perubahan biologis, psikologis, dan psikososial sebagai akibat pertumbuhan dan perkembangan kejiwaan manusia. Pendidikan seks dalam Kalender Kartun Ceria (Cerita Remaja Indonesia) Biologi ini membekali pengetahuan kepada para siswa tentang fungsi organ reproduksi dengan menanamkan moral, etika serta agama agar tidak terjadi penyalahgunaan organ reproduksi tersebut. Sehingga pendidikan seks dalam Kalender Kartun Ceria (Cerita Remaja Indonesia) Biologi ini menyampaikan pesan moral kepada para siswa dalam kehidupannya.

Pada kelayakan penyajian, Kalender Kartun Ceria (Cerita Remaja Indonesia) ini menyajikan gambar mengenai sistem reproduksi dengan baik sesuai siswa remaja kelas IX SMP. Dimana dalam penyajian gambar pada Kalender Kartun Ceria (Cerita Remaja Indonesia) Biologi ini menyajikan tema pendidikan seks untuk menunjang materi sistem reproduksi dengan menampilkan gambar bentuk dari organ reproduksi, siklus reproduksi, dan penyakit pada sistem reproduksi sesuai dengan tahap perkembangan dewasa siswa remaja itu sendiri.

Pada kelayakan bahasa, Kalender Kartun Ceria (Cerita Remaja Indonesia) ini menyampaikan bahasa yang memudahkan siswa remaja dengan mudah memahami pendidikan seks pada materi sistem reproduksi yang memuat pada Kalender Kartun Ceria (Cerita Remaja Indonesia) Biologi ini. Kalender Kartun Ceria (Cerita Remaja Indonesia) Biologi ini menyampaikan dan menyajikan bahasa seperti kosakata, kalimat, paragrap dan wacana disajikan dengan baik sesuai dengan kaidah-kaidah Bahasa Indonesia.

Pada kelayakan desain, Kalender Kartun Ceria (Cerita Remaja Indonesia) ini menampilkan desain gambar yang baik dan benar sesuai dengan karakter pendidikan siswa pada usia remaja pada tahap pendewasaan siswa. Dengan menggambarkan desain gambar yang sesuai dengan karakter siswa remaja, maka siswa dapat mengenal bagaimana organorgan seksualitas itu, siklus menstruasi, kesehatan mengenai organ seksualitas, dan penyakit yang menyerang pada organ seksualitas tersebut. Sehingga remaja dapat mengetahui permasalahan seputar seks secara benar dan penuh tanggung jawab.

Hasil dari validator ahli pada Kalender Kartun Ceria (Cerita Remaja Indonesia) ini divalidasi sebagai perangkat pembelajaran Kalender Kartun Ceria (Cerita Remaja Indonesia) yang dapat dimanfaatkan kepada para siswa dalam memahami materi pembelajaran sistem reproduksi dengan baik. Selain validasi dari para ahli, juga dilakukan penilaian kepada para Guru Biologi terhadap Kalender Kartun Ceria (Cerita Remaja Indonesia) Biologi Kelas IX SMP PGRI 24 Medan. Penilaian Guru Biologi terhadap Kalender Kartun Ceria (Cerita Remaja Indonesia) dinilai berdasarkan kelayakan: isi, penyajian, bahasa, dan desain. Berdasarkan hasil penilaian dari guru biologi terhadap Kalender Kartun Ceria (Cerita Remaja Indonesia) diperoleh secara keseluruhan bahwa Kalender Kartun Ceria (Cerita Remaja Indonesia) ini yang menyajikan pengetahuan tentang pendidikan seks sangat baik digunakan sebagai penunjang materi sistem reproduksi bagi siswa Kelas IX SMP. Penilaian Validasi Ahli dan Penilaian Guru Biologi terhadap Kalender Kartun Ceria (Cerita Remaja Indonesia) disajikan pada Tabel 1. 
Tabel 1. Penilaian Validator Ahli dan Penilaian Guru Biologi terhadap Kalender Kartun Ceria (Cerita Remaja Indonesia)

\begin{tabular}{ll}
\hline Penilaian & \multicolumn{1}{c}{ Keterangan } \\
\hline Validator Ahli & $\begin{array}{l}\text { Perangkat pembelajaran Kalender Kartun Ceria (Cerita Remaja Indonesia) } \\
\text { dinyatakan valid dan dapat dimanfaatkan kepada para siswa dalam } \\
\text { membantu memahami materi pembelajaran sistem reproduksi dengan }\end{array}$ \\
& $\begin{array}{l}\text { baik. } \\
\text { Kalender Kartun Ceria (Cerita Remaja Indonesia) ini yang menyajikan } \\
\text { pengetahuan tentang pendidikan seks sangat baik digunakan sebagai } \\
\text { penunjang materi sistem reproduksi bagi siswa Kelas IX SMP. }\end{array}$ \\
\hline
\end{tabular}

Penilaian Guru Biologi terhadap Kalender Kartun Ceria (Cerita Remaja Indonesia) disajikan pada Tabel 2.

Tabel 2. Penilaian Guru Biologi terhadap Kalender Kartun Ceria (Cerita Remaja Indonesia)

\begin{tabular}{cccc}
\hline Aspek Kelayakan & Rata-rata & Persen $(\%)$ & Kategori \\
\hline Isi & 2,94 & 73,50 & Baik \\
Penyajian & 3,08 & 77,00 & Sangat Baik \\
Bahasa & 2,86 & 71,50 & Baik \\
Desain & 3,05 & 76,25 & Sangat Baik \\
\hline
\end{tabular}

Dengan demikian Kalender Kartun Ceria (Cerita Remaja Indonesia) ini memiliki keunggulan dibanding dengan sumber belajar lain atau buku ajar biologi lain yang memuat materi sistem reproduksi karena Kalender Kartun Ceria (Cerita Remaja Indonesia) berisikan materi sistem reproduksi yang diapik sederhana, menarik dan kreatif agar anak-anak merasa senang membaca dan tidak merasa bosan dengan tampilan lucu didalamnya. Dengan plot yang sederhana sehingga materi sistem reproduksi dapat dengan mudah dipahami oleh siswa serta menjadi pusat perhatian dan menjadi alat penyentuh emosi dan pola pikir siswa. Ilustrasi Kalender Kartun Ceria (Cerita Remaja Indonesia) berisikan teks informasi bagi pembaca khususnya siswa pra remaja kelas IX SMP PGRI 24 Medan dengan menggunakan gaya penulisan yang luas dan beragam. Pada segi pewarnaan Kalender Kartun Ceria (Cerita Remaja Indonesia) ini menggunakan warna-warna yang menarik dan Ceria (Cerita Remaja Indonesia). Bahasa yang digunakan juga menggunakan bahasa yang dengan mudah dipahami kaum remaja agar mudah memahami isi dari materi sistem reproduksi pada kalender kartun Ceria (Cerita Remaja Indonesia) tersebut.

\section{Tahap Disseminate (Penyebaran)}

Tahap disseminate (penyebaran) dalam penelitian ini yaitu melakukan uji coba Kalender Kartun Ceria (Cerita Remaja Indonesia) kepada para siswa kelas IX SMP PGRI 24 Medan secara bertahap yakni Uji Coba Perseorangan, Uji Coba Kelompok Kecil, dan Uji Lapangan Terbatas.

\section{A. Uji Coba Perseorangan}

Hasil Uji Coba Perseorangan yang dilakukan pada 3 siswa secara kesuluruhan diperoleh bahwa Kalender Kartun Ceria (Cerita Remaja Indonesia) ini memiliki tampilan yang baik sehingga dapat memberikan minat dan sangat memotivasi siswa untuk membaca. Dengan demikian Kalender Kartun Ceria (Cerita Remaja Indonesia) ini yang menyajikan pengetahuan tentang pendidikan seks yang sangat baik digunakan sebagai sumber informasi untuk menunjang materi sistem reproduksi bagi siswa Kelas IX SMP. Persepsi Siswa terhadap Kalender Kartun Ceria (Cerita Remaja Indonesia) pada Uji Coba Perseorangan disajikan pada Tabel 3. 
Tabel 3. Persepsi Siswa terhadap Kalender Kartun Ceria (Cerita Remaja Indonesia) pada Uji Coba Perseorangan

\begin{tabular}{lccc}
\hline Indikator Penilaian & Rata-rata & Persen $(\boldsymbol{\%})$ & Kategori \\
\hline Tampilan Kalender Kartun & 2,92 & 73,00 & Baik \\
Ceria & 3,33 & 83,25 & Sangat Baik \\
Penguasaan Materi & 3,44 & 86,00 & Sangat Baik \\
Motivasi Belajar & 3,33 & 83,25 & Sangat Baik \\
Sumber Informasi & & & \\
\hline
\end{tabular}

\section{B. Uji Coba Kelompok Kecil}

Hasil Uji Coba Perseorangan yang dilakukan pada 9 siswa secara kesuluruhan diperoleh bahwa siswa termotivasi untuk membaca karena tampilan kalender ini sangat baik Kalender Kartun Ceria (Cerita Remaja Indonesia) ini memiliki tampilan yang sangat baik sehingga dapat memberikan minat kepada siswa dan memotivasi dengan baik kepada siswa untuk membaca. Dengan demikian Kalender Kartun Ceria (Cerita Remaja Indonesia) ini yang menyajikan pengetahuan tentang pendidikan seks yang baik digunakan sebagai sumber informasi untuk menunjang materi sistem reproduksi bagi siswa Kelas IX SMP. Persepsi Siswa terhadap Kalender Kartun Ceria (Cerita Remaja Indonesia) pada Uji Coba Kelompok Kecil disajikan pada Tabel 4.

Tabel 4. Persepsi Siswa terhadap Kalender Kartun Ceria (Cerita Remaja Indonesia) pada Uji Coba Kelompok Kecil

\begin{tabular}{lccc}
\hline Indikator Penilaian & Rata-rata & Persen $(\%)$ & Kategori \\
\hline Tampilan Kalender & 3,11 & 77,75 & Sangat Baik \\
Kartun Ceria & 2,85 & 71,25 & Baik \\
Penguasaan Materi & 2,96 & 74,00 & Baik \\
Motivasi Belajar & 2,52 & 63,00 & Baik \\
Sumber Informasi & & & \\
\hline
\end{tabular}

\section{Uji Lapangan Terbatas}

Hasil Uji Coba Perseorangan yang dilakukan pada 28 siswa secara kesuluruhan diperoleh bahwa Kalender Kartun Ceria (Cerita Remaja Indonesia) ini memberikan minat dan memotivasi siswa untuk membaca kaarena memiliki tampilan yang sangat baik. Dengan demikian Kalender Kartun Ceria (Cerita Remaja Indonesia) ini yang menyajikan pengetahuan tentang pendidikan seks yang baik digunakan sebagai sumber informasi untuk menunjang materi sistem reproduksi bagi siswa Kelas IX SMP. Persepsi Siswa terhadap Kalender Kartun Ceria (Cerita Remaja Indonesia) pada Uji Lapangan Terbatas disajikan pada Tabel 5.

Tabel 5. Persepsi Siswa terhadap Kalender Kartun Ceria (Cerita Remaja Indonesia) pada Uji Lapangan Terbatas

\begin{tabular}{lccc}
\hline Indikator Penilaian & Rata-rata & Persen $(\boldsymbol{\%})$ & Kategori \\
\hline Tampilan Kalender & 3,22 & 80,50 & Sangat Baik \\
Kartun Ceria & & & \\
Penguasaan Materi & 2,99 & 74,75 & Baik \\
Motivasi Belajar & 3,14 & 78,50 & Sangat Baik \\
Sumber Informasi & 2,85 & 71,25 & Baik \\
\hline
\end{tabular}




\section{Kelayakan Isi Kalender Kartun Ceria (Cerita Remaja Indonesia)}

Kalender Kartun Ceria (Cerita Remaja Indonesia) Biologi ini memiliki kriteria yang baik digunakan kepada para siswa remaja khususnya kelas IX SMP. Dimana dalam bentuk penyajian isi Kalender Kartun Ceria (Cerita Remaja Indonesia) Biologi memuat tentang pendidikan seks. Dimuatnya pendidikan seks dalam Kalender Kartun Ceria (Cerita Remaja Indonesia) Biologi ini bertujuan untuk menanggulangi degradasi moral yang seyogyanya menjadi perhatian dalam dunia pendidikan di Indonesia.

Pendidikan seks yang dimuat dalam Kalender Kartun Ceria (Cerita Remaja Indonesia) Biologi ini memberikan pengetahuan tentang perubahan biologis, psikologis, dan psikososial sebagai akibat pertumbuhan dan perkembangan kejiwaan manusia. Pendidikan seks dalam Kalender Kartun Ceria (Cerita Remaja Indonesia) Biologi ini membekali pengetahuan kepada para siswa tentang fungsi organ reproduksi dengan menanamkan moral, etika serta agama agar tidak terjadi penyalahgunaan organ reproduksi tersebut. Sehingga pendidikan seks dalam Kalender Kartun Ceria (Cerita Remaja Indonesia) Biologi ini menyampaikan pesan moral kepada para siswa dalam kehidupannya.

Pendidikan seks merupakan cikal bakal pendidikan kehidupan siswa untuk berkeluarga. Sehingga memiliki peranan penting bagi para siswa khususnya siswa remaja untuk mengenal pendidikan seks yang sesuai dengan tahap perkembangan kedewasaan mereka. Oleh karenanya dengan mengkaji pendidikan seks kepada para siswa remaja dapat diketahui pula sejauh mana siswa mengkaji kebutuhan kehidupannya. Karena selama ini pendidikan seks hanya disempitkan hanya pada aspek pembelajaran dalam hubungan seks saja, tidak pada kesehatan seks dalam menjaga dan merawat kesehatan organ seksualitas, dan dampak penyalahgunaan seksualitas dalam kehidupan dan gaya hidup seksualitas yang tidak patut dicontoh atau dilakukan demi masa depan siswa khususnya siswa remaja itu sendiri. Sebagaimana hasil penelitian dari Barroh (2012) dalam pengembangan buku ajar berjendela pada materi sistem reproduksi manusia untuk SMP RSBI berupa Flap Book yang sangat membantu dalam meringkas materi/konsep pada pembelajaran science sehingga terlihat lebih fokus materi yang lebih ringkas dan lebih terfokus ini membantu siswa siswa mencerna informasi dengan lebih baik.

Oleh karena itu, pendidikan seks bukanlah suatu hal yang tabu untuk diketahui oleh para siswa yang pada akhirnya remaja mencari jalan untuk mencari informasi seks dari sumber-sumber lain seperti buku bacaan, gambar, dan film yang berbau pornografi. Seksualitas tidak boleh di pandang tabu. Membiarkan sikap anak yang salah terhadap informassi seks yang diwarisi karena asuhan, didikan, dan persepsi orang tua maupun guru mereka yang keliru terhadap seks dan seks mengakibatkan organ seks mereka kelak tidak sehat. Maka, orang dewasa berperan penting dalam pendampingan mereka menghadapi masamasa pertumbuhan menuju kedewasaanya, sehingga anak remaja mulai sekarang harus diberikan pendidikan seks usia dini yang tepat dan benar.

\section{Kelayakan Penyajian Kalender Kartun Ceria (Cerita Remaja Indonesia)}

Kalender Kartun Ceria (Cerita Remaja Indonesia) Biologi ini menyajikan gambar mengenai sistem reproduksi dengan baik sesuai siswa remaja kelas IX SMP. Dimana dalam penyajian gambar pada Kalender Kartun Ceria (Cerita Remaja Indonesia) Biologi ini menyajikan tema pendidikan seks untuk menunjang materi sistem reproduksi dengan menampilkan gambar bentuk dari organ reproduksi, siklus reproduksi, penyimpangan dan penyakit pada sistem reproduksi sesuai dengan tahap perkembangan dewasa siswa remaja itu sendiri, misalnya dengan memberikan pengetahuan tentang bahayanya pergaulan bebas dan hubungan seks tanpa ikatan pernikahan yang sah. 
Pada masa remaja khususnya siswa kelas IX SMP sangat membuat orang tua siswa akan selalu dipusingkan dengan perubahan perilaku anak-anaknya tentang perubahan yang terjadi pada diri siswa terhadap tanda-tanda timbulnya organ seksualitas yang tumbuh pada diri siswa remaja tersebut. Maka dari itu tidak ada alasan bagi orang tua untuk tidak mendiskusikan masalah seks kepada anaknya yang telah menginjak dewasa. Dimana, pada masa ini akan terjadi perkembangan fisik dan mental yang berbeda pada anak laki-laki dan perempuan ketika tumbuh menjadi dewasa. Sehingga pendidikan seks akan sangat penting untuk diberikan pembelajaran mengenai pendidikan seks pada masa remaja. Oleh karena itu, para pemerhati masalah remaja berpendapat bahwa penyebaran seks bebas salah satunya disebabkan karena minimnya pengetahuan remaja tentang seksualitas. Sebagaimana hasil penelitian dari Budianto (2015) dalam pengembangan perancangan buku interaktif pra pubertas untuk anak perempuan usia 8 hingga 13 tahun ini dibuat untuk melalukan pendekatan kreatif melalui buku cerita bergambar yang interaktif.

Kalender Kartun Ceria (Cerita Remaja Indonesia) menyajikan gambar dengan baik dan benar sesuai dengan karakter pendidikan siswa pada usia remaja pada tahap pendewasaan siswa, sehingga siswa dapat mengenal bagaimana organ-organ seksualitas itu, siklus menstruasi, kesehatan mengenai organ seksualitas, dan penyimpangan serta penyakit yang menyerang pada organ seksualitas tersebut. Dengan demikian, perlu bagi remaja untuk mengetahui permasalahan seputar seks secara benar dan penuh tanggung jawab. Dalam konteks pendidikan seks pada usia remaja tidak lagi seputar identifikasi laki-laki dan perempuan atau identifikasi pubertas saja, namun lebih luas lagi bahkan sampai pada masalah moral.

\section{Kelayakan Bahasa (Keterbacaan) Kalender Kartun Ceria (Cerita Remaja Indonesia)}

Penyampaian bahasa dari Kalender Kartun Ceria (Cerita Remaja Indonesia) Biologi ini memiliki penyampaian bahasa yang baik bagi para siswa remaja. Penyampaian bahasa yang memudahkan siswa remaja dengan mudah memahami pendidikan seks pada materi sistem reproduksi yang memuat pada Kalender Kartun Ceria (Cerita Remaja Indonesia) Biologi ini. Kalender Kartun Ceria (Cerita Remaja Indonesia) Biologi ini menyampaikan dan menyajikan bahasa seperti kosakata, kalimat, paragrap dan wacana disajikan dengan baik sesuai dengan kaidah-kaidah Bahasa Indonesia. Metsala dan Glynn (1996) menyatakan bahwa buku ajar memiliki peran yang sangat penting dalam proses belajar mengajar karena dapat menguatkan dan mendukung informasi materi yang disampaikan oleh guru dalam pembelajaran agar berkembang, mudah diingat, dan dapat diulang-ulang agar infomasi tersebut.

Oleh karena itu penyampaian bahasa yang baik merupakan komunikasi penting dari Kalender Kartun Ceria (Cerita Remaja Indonesia) Biologi ini kepada para siswa remaja untuk memahami pendidikan seks pada materi sistem reproduksi serta dapat menimbulkan minat baca siswa sehingga memudahkan siswa untuk memiliki motivasi belajar dengan lebih baik lagi. Sebagaimana hasil penelitian dari Helmi (1998) efektivitas pendidikan seksual dini dalam meningkatkan pengetahuan perilaku seksual sehat. Pendidikan seksual dini yang paling efektif adalah kepada orang tua dalam meningkatkan pengetahuan perilaku seksual sehat.

Gultom (2012) yang menyatakan bahwa materi buku ajar hendaknya menyampaikan informasi pengetahuan dengan bahasa yang sederhana, lugas, dan mudah dipahami serta bersifat komunikatif khususnya bagi para siswa. Hasil penelitian ini didukung hasil penelitian Ramansyah (2013) yang menyimpulkan bahwa melalui penyusunan buku ajar yang baik dapat memudahkan proses pembelajaran dan memiliki daya tarik serta mampu memotivasi 
siswa untuk lebih aktif dalam proses pembelajaran, lebih interaktif, dan lebih kritis dalam menjawab masalah-masalah dalam proses pembelajaran biologi.

Dengan penyampaian bahasa yang sesuai dengan EYD yang benar, serta menggunakan peristilahan yang sesuai dengan konsep pokok bahasan yang tepat. Maka, Kalender Kartun Ceria (Cerita Remaja Indonesia) Biologi ini dapat dengan mudah dipahami siswa remaja mengenai pendidikan seks pada materi sistem reproduksi dan mengerti pesan moral dari Kalender Kartun Ceria (Cerita Remaja Indonesia) Biologi tersebut.

\section{KESIMPULAN}

Hasil penelitian ini diperoleh bahwa: (1) Kelayakan Isi Kalender Kartun Ceria (Cerita Remaja Indonesia) diperoleh dengan kriteria kelayakan baik, (2) Kelayakan Penyajian Kalender Kartun Ceria (Cerita Remaja Indonesia) diperoleh dengan kriteria kelayakan sangat baik, (3) Kelayakan Bahasa (Keterbacaan) Kalender Kartun Ceria (Cerita Remaja Indonesia) diperoleh dengan kriteria kelayakan baik, dan (4) Kelayakan Desain Kalender Kartun Ceria (Cerita Remaja Indonesia) diperoleh dengan kriteria kelayakan sangat baik. Hasil penelitan ini mengimplikasikan bahwa Kalender Kartun Ceria (Cerita Remaja Indonesia) Biologi ini memiliki kriteria yang baik untuk digunakan kepada para siswa remaja khususnya kelas IX SMP dalam menyampaikan informasi pengetahuan mengenai pendidikan seks dalam menunjang materi sistem reproduksi di dalam kelas.

\section{DAFTAR PUSTAKA}

Anggela, M. (2013). Pengembangan Buku Ajar Bermuatan Nilai- nilai Karakter Pada Materi Usaha dan Momentum untuk Pembelajaran Fisika Siswa Kelas XI SMA. Pillar of Physics Education. Vol.1, Halaman: 63-70.

Budianto, dkk. (2015). Perancangan Buku Interaktif Pra Pubertas Untuk Ank Perempuan Usia 8 Hingga 13 Tahun.

Barroh, dkk. (2013). Pengembangan buku Ajar Berjendela Pada Materi Sistem Reproduksi Manusia Untuk SMP RSBI. Jurnal Biology Education. Vol 1 (2): 1-9.

Gultom, S. (2012). Pedoman Penulisan Buku Ajar Peningkatan Kompetensi Pendidik Pendidikan Nonformal. Jakarta. Kemendikbud.

Helmi, dkk. (1998). Efektivitas Pendidikan Seksual Dinni Dalam Meningkatan Pengetahuan Perilaku Seksual Sehat. Jurnal Psikologi (2) :24-34.

Hurlock, E.B. (1978). Child Development. Erlangga. Jakarta.

Metsala, J.L, and Glynn, S. (1996). Teaching With Analogies : Buildings On The Science Text Book. The Reading Teacher, 49 (6) : 490-492.

Ramansyah, W. (2013). Pengembangan Bahan Ajar Mata Kuliah Strategi Pembelajaran untuk Mahasiswa Pendidikan Guru Sekolah Dasar. Madura Bangkalan. Jurnal Widyagogik, Volume1 Nomer 1.

Sagala, R., Djulia, E. (2016) Pengaruh Model Kooperatif Tipe Think Pair Share berbantuan Video Pembelajaran terhadap hasil belajar dan sikap siswa pada materi Sistem Reproduksi Manusia. Jurnal Pelita Pendidikan Volume 4 (2)

Sapitri, A., Djulia, E., Sipahutar, H. (2014) Hubungan Metakognitif tentang Kesehatan Reproduksi dengan Persepsi Perilaku Seksual Siswa SMA Se-Kota Medan. UNIMED Digital Repository, 2014/8/23, 471-479

Supriadi, D. 2001. Anatomi Buku Sekolah di Indonesia. Yogyakarta: Adi Cita Karya Nusa.

Syamsi, K. 2013. Pengembangan Model Buku Ajar Membaca Berdasarkan Pendekatan Proses Bagi Siswa SMP. Yogyakarta. Jurnal Cakrawala Pendidikan Th.XXXII No 1. 
Jurnal Biogenesis Vol. 17 (2): 69-80, 2021

(C) Program Studi Pendidikan Biologi FKIP Universitas Riau e-ISSN : 2776-1924

Thiagarajan, S., Semmel, D. S \& Semmel, M. I. 1974. Instructional Development for TrainingTeachers of Expectional Children. Minneapolis, Minnesota: Leadership TrainingInstitute/Special Education, University of Minnesota. 